\title{
Ethics And Culture: Is there A Relationship?
}

Gary Saunders, Marshall University, USA

T. Maurice Lockridge, Marshall University, USA

\begin{abstract}
With the dramatic increase in international business, companies are faced with increased differences in business rules and behaviors between locations. Location to location differences in business norms and practices leads to the question if there is a relationship between ethics and culture? The emergence of Asian countries as economic forces and larger trading partners to the West has heightened the cultural differences. This paper looks at the ethical attitudes of U.S. students relative to the ethical attitudes of students in India. This paper found that Indian students and U.S. students exhibited very similar attitudes toward ethics and unethical acts, despite perceived ethical differences between the cultures.
\end{abstract}

Keywords: Bribery, Culture, Ethics, Ethnicity, Honesty, Judgment, Principles, Values

\section{INTRODUCTION}

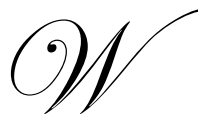

ith the dramatic increase in globalization in the 21st century, businesses are facing a corresponding increase in corruption concerns when expanding overseas. In the US, the number of bribery related enforcement actions initiated by the Securities and Exchange Commission (SEC) and Department of Justice (DOJ) in the last seven years has far exceeded the total number of such enforcement actions initiated in the first 23 years after the Foreign Corrupt Practices Act (FCPA) was first adopted. (Gerlach, et/al., 2008)

The quote above aptly describes a problem facing the international business community. Ethical problems in the US business community have been widely publicized and, in many cases prosecuted and punished. The global problem is more complex in that it reaches across international boundaries and cultures. The emergence of Asian countries as economic forces has added to the ethical dilemma. In its 2007 Transparency International Corruption Perceptions Index (transparency.org) China and India were given a score of 3.5 on a 10 point scale. This ranking for two of the world's largest countries is far below most other industrialized countries and indicates a widespread perception of extensive corruption. This ethics problem has resulted in stepped-up enforcement by the United States and other countries. The UN Convention Against Corruption (convention) was adopted in 2003 and signed by 111 countries and, by 2005 , the number of countries had risen to 133 . The convention recognized the global nature of the problem and called on the signers to promote measures to prevent and combat corruption and to support international cooperation and technical assistance in the prevention of corruption.

The FCPA and the convention both address an ethical problem that may be caused, at least in part, by cultural attitudes and mores. Many studies have been conducted in efforts to understand what motivates an individual to act ethically, or unethically. Results of those studies have been, at best, mixed.

\section{PREVIOUS STUDIES}

Studies by Cohen et a1. (2001), O'Leary and Cotter (2000), Glover et a1. (2002), Sankaran and Bui (2003), Allmon et. a1. (2000), are attempts to determine which factors, such as demographic characteristics, personal values, or cultural differences, might influence ethical behaviors. Allmon et al. (2000) studied some factors that might affect business students' ethical beliefs and their perceptions of ethical classroom behavior. They considered attitudes toward cheating in the classroom as an indication of future business ethics. Their results indicated 
differences in ethical behavior based on personality preferences, country of origin, age, religious orientation and gender.

O'Leary and Cotter (2000) examined the ethical attitudes of final year accountancy students in Ireland and Australia in an effort to determine if culture has an effect on ethical decision-making. The survey instrument contained six ethical scenarios each with three choices of action. Participants could accept a bribe/offer, reject the bribe/offer and say nothing, or reject the bribe/offer and report to the relevant authorities. Irish students were found to be more ready to act unethically than were their Australian contemporaries. Additionally, males in both countries appeared more likely to act unethically than female students. But the inclination towards unethical actions dropped dramatically when an element of risk was introduced, suggesting that the risk of getting caught would make individuals act more ethically. Factors that were believed to contribute to the differences between the respondents in the two countries include sensitivity of the business environments towards ethics issues, legal protection afforded to whistle blowers and the emphasis on ethics through education.

Saunders and Wenzel [2007] found that ethical attitudes differed between cultures. They found, in a study of 418 students, that Asians were more accepting of bribery and cheating than were U.S. students and more likely to believe more strongly that they would benefit from unethical behavior. Asians also believed that the negative consequences of unethical actions were less likely to be experienced.

Buckley argued that individuals who believe they are ethical while simultaneously perceiving that unethical behavior is common, might as be inclined to engage in unethical behavior in order to compete on even ground despite believing that the actions are morally wrong (Buckley et al. 1997, as quoted by Manley et al., 2001). Perhaps Asians perceive that bribery and corruption are widespread in their societies and, consequently, are more accepting of bribery and cheating.

\section{THE CURRENT STUDY}

In a previous study by Saunders and Wenzel (2007), a questionnaire was developed to measure attitudes toward bribery and cheating. The original questionnaire contained 19 statements relating to the research questions and four demographic questions. The 19 statements were combined to make five scales with the scales being validated using Cronbach's "coefficient alpha." Statements were randomly arranged, as much as possible, consistent with similar response scales. The validation process resulted in the elimination of three of the statements and the remaining 16 were used in the current study.

The study by Saunders and Wenzel (2007) contained responses from 418 students in a medium sized Midwestern university. As shown in Figure 1, 29 of those 418 students indicated they were Asian and 7 checked "other." Undoubtedly, some of these 29 Asians were either born in the U.S. or had lived here long enough to reflect U.S. views on bribery and corruption. However, the structure of the data did not permit the separation of these responses. These 36 (29 Asians and 7 "other") responses were removed from the data set to provide a new data set of 382 responses consisting of Caucasian, African American and Hispanic. These groups were considered to be reasonably representative of U.S. students.

\section{Ethnicity US Students}

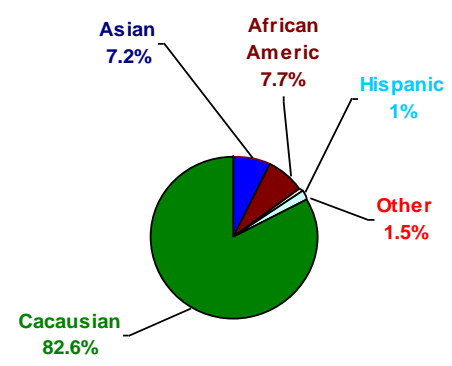

Figure 1 
A second data set has been obtained containing responses of 34 Indian students to the same questionnaire. Comparison of these responses with the 382 responses from the previous study will provide more evidence of a possible cultural effect.

\section{RESULTS}

Appendix I contains the average responses for the 382 U.S. students and for the 34 Indian students to each statement and the significance of the difference between the means. Differences between the means which are significant at the 0.05 level are boldfaced. Average responses to only three of the sixteen statements indicated significant differences, at the 0.05 level, indicating a great deal of similarity in the attitudes of the two groups toward the statements.

\section{Statements}

Responses to the first statement, "honesty is always the best policy," indicate that students in both groups agree with the statement and there is no significant difference in their level of agreement. Students are generally indifferent (neither agree nor disagree) to the second statement, "other people's welfare is more important than mine," but Indian students are significantly more agreeable than are U.S. students. Both groups of students agreed with the third statement that "I will never tolerate bribery in my life" but Indian students agreed more strongly.

When asked how important "self-principles" were in making ethical decisions, both groups indicated that they were very important to important. No significant ( 0.05 level) difference was found between the two groups as to their level of importance. Responses to a second factor, "law or regulations," indicate that they are slightly less important than self principles but still important. Again, Indian students attached more importance, but not significantly more, than did U.S. students.

Students were asked to indicate their level of agreement with statements relating to integrity, bribery and cheating. Responses to the statement that "reporting a financial malpractice is required only if it involves a lot of money" revealed that while students tended to disagree with the statement, they did not strongly disagree. When asked if "bribery is acceptable if it is customary in the present environment," students in both groups again disagreed, but not strongly. No significant differences were found between the mean responses of the two groups to either of these two statements. A third statement, relating to cheating, said "in some situations cheating is the right thing to do." Responses indicate that students in both groups disagree with the statement and that U.S. students disagree significantly ( 0.001 level) more strongly than do Indian students that cheating is never the right thing to do.

Other statements related to the perceived positive and negative consequences of taking and unethical action. Students were asked how likely the positive and negative consequences were, with response categories ranging from "highly unlikely" to "highly likely." Responding to the first statement that "I will get a lot of money" from taking an unethical action, students believed that it was not likely. A similar response was observed to the statement that "I will enjoy a better lifestyle" with U.S. students believing it was slightly more likely. Another statement said "I will have better business opportunities" as a result of taking an unethical action. Again, the respondents did not believe that it was likely to occur. The last positive consequence, "I will become more competitive" was also not believed to be an outcome. No significant differences were found between responses to any of the four possible positive consequences for the two groups.

Students were also asked about the likelihood of experiencing negative consequences from taking an unethical action. Responses to one statement that "I will be legally punished" for taking an unethical action were again neutral; neither believing it was likely or unlikely. Students responded in a similar manner to the statement that "I will lose my job" indicating that it was not likely. A third statement said "I will humiliate myself" and responses indicated that this result was not likely. Apparently students would not feel humiliated by taking an unethical action. The last statement relating to negative consequences said "I will humiliate my family." Students did not feel they would humiliate their family by taking an unethical action. 
Scales

The 16 statements were added to generate scales as indicated by the grouping in Appendix II. As indicated earlier, the scales were validated using Cronbach's "coefficient alpha" and some of the original statements were eliminated. The five scales were "Ethics Principles," "Personal Values," "Ethical Judgment," "Perceived Positive Consequences of Unethical Actions" and "Perceived Negative Consequences of Unethical Actions." Appendix II contains average responses to each scale for the two groups and the significance of the difference between their means.

The statements "honesty is always the best policy," “other people's welfare is more important than mine," and "I will never tolerate bribery in my life" were summed for each respondent to obtain the scale for "Ethics Principles." Both groups displayed positive ethics principles by agreeing to the three statements in the scale. Indian students indicated significantly stronger ethical principles than did the U.S. students.

The "Personal Values" scale consisted of two statements relating to "self-principles" and "law or regulations" and how important they are in making ethical decisions. Both Indian and U.S. students indicated that they were important in making ethical decisions but the Indian students indicated they were significantly more important.

The third scale, "Ethical Judgment," contained the statements "reporting a financial malpractice is required only if it involves a lot of money," "bribery is acceptable if it is customary in the present environment," and "in some situations cheating is the right thing to do." Both groups indicated positive ethical judgment by disagreeing with the statements contained in the scale. As seen in Appendix II, U.S. students disagreed with the statements significantly more strongly than did Indian students.

The "Perceived Positive Consequences" was made up of four statements; "I will get a lot of money," "I will enjoy a better lifestyle," "I will have better business opportunities," and "I will become more competitive." Both groups were essentially neutral on whether they would realize any benefit from taking an unethical action. There was no significant difference between their responses.

The last scale, "Perceived Negative Consequences," contained "I will be legally punished," "I will lose my job," "I will humiliate myself," and "I will humiliate my family." As with the positive consequences, both groups indicated that they were not likely to incur the negative consequences if they performed an unethical act and, there was no significant difference in the means of their responses.

\section{SUMMARY}

Indian students and U.S. students exhibited very similar attitudes toward ethics and unethical acts. When a significant difference was observed, the Indian students expressed stronger ethical attitudes than did U.S. students. The exception to this was that Indian students were more accepting of cheating.

These results are contrary to the results found in the Saunders and Wenzel study where Asian students in the U.S., and Malaysian students, were significantly (at the 0.000 level) more accepting of the excuses for unethical actions, ethical judgment, than were Caucasians and more likely to believe (at the 0.000 level) that they would benefit from unethical behavior. Asians in the U.S. also believed (at the 0.059 level of significance) that the negative consequences of unethical actions were less likely to be experienced than did Caucasians.

In the previous study, the responses from Asians in the U.S. were compared to the responses of participants in the Ahmad \& Fadzly (2004) study. The data indicated that the beliefs of Asians in the U.S. were more comparable to those Asians in the Ahmad \& Fadzly study than to the beliefs of the other participants in the previous study. The level of acceptance of unethical actions by Asians in the previous study was about as high as the level recorded by Malaysians in the Ahmad \& Fadzly study, which was substantially higher than that of the others in the previous study. Overall, Asians in the previous study appear to have opinions more like the Malaysians than like the other respondents in the present study and appear to be different from those of Indian participants. This observation of the similarities suggests that cultural differences are a substantial factor in ethical decision making, which is 
consistent with the findings of the O'Leary and Cotter (2000) study, but contrary to the attitudes of Indian students in this study.

What may be confounding the results is "self-enhancement bias" where people tend to evaluate themselves more favorable than others (Alicke et aI., 1995, as quoted by Manley et aI., 2001). Self-enhancement bias will cause an individual to describe oneself more positively than the social norm. Manley et a1. (2001) also noted that, based on prior research, self-enhancement bias can occur in situations involving ethics perceptions, though the bias is reduced when the factors of being caught and punished are present. In this study, the possibility of being caught and punished did not seem to be a concern.

Summarily, students in a culture that is generally believed to be more corrupt than Western cultures exhibited ethical principles as strong, or stronger, than did students in the U.S.

\section{AUTHOR INFORMATION}

Gary Saunders, DBA, CPA earned his doctorate at the University of Kentucky in 1977. He joined the faculty at Marshall University in 1990 and is currently Professor of Accountancy and Elizabeth McDowell Lewis Chair in the LCOB at Marshall. Dr. Saunders has published extensively and has authored two accounting simulation textbooks, a cost accounting textbook and a spreadsheet textbook. He operates Integrated Business Systems, a publishing company.

T. Maurice Lockridge, PhD, CPA earned his doctorate at the University of Memphis in 2004. He is currently an Assistant Professor of Accountancy in the Lewis College of Business at Marshall University in Huntington, WV where he teaches accounting at the introductory as well as the graduate level.

\section{REFERENCES}

1. Ahmad, Zauwiyah \& Fadzly, Mohamed Nazri F., presented at the $5^{\text {th }}$ Annual Conference of the Asian Academic Accounting Association, October 11-13, 2004.

2. Allmon, D.E., Page, D., \& Roberts, R. (2000). Determinants of perceptions of cheating: Ethical orientation, personality and demographics. Journal of Business Ethics, 23 (4), pp. 41 1-422.

3. Armstrong, M.B., Ketz, 1.E., \& Owsen, D. (2003). Ethics education in accounting: moving toward ethical motivation and ethical behavior. Journal of Accounting Education, 21, pp. 1-16.

4. Brief, A. Dukerich, J., \& Doran, L. (J 990). Resolving ethical dilemmas in management: experimental investigation of values, accountability and choice. Journal of Applied SocialPsychology, 21(5), pp. 380396.

5. Buckley, M.R., Wiese, D.S., \& Harvey, M.G. (1998). An investigation into the dimensions ofunethical behavior. Journal of Education for Business, May/June, pp. 284-290.

6. Cohen, J. R., Pant, L.W., \& Sharp, D.J. (2001). An examination of differences in ethical decision-making between Canadian business students and accounting professionals. Journal of Business Ethics, 30 (4), pp. 319-336.

7. Gerlach, Paul V, Shubert, Leslie, Zhengyu, Tang \& Sidley, Austin, “Anti-bribery laws: regulation, risk and prevention in the life sciences industries, PLC Cross-Border Life Sciences Handbook 2007/08, Practical Law Company, www.practicallaw.com/7-378-8724.

8. Glover, S.H., Bumpus, M.A., Sharp, G.F, \& Munchus, G.A. (2002). Gender differences in ethical decision making. Women in Management Review, 17(5), pp. 217-227.

9. http://www.transparency.org/policy_research/surveys_indices/cpi/2007

10. Manley, G.G., Russel, C.J., \& Buckley, M.R. (2001). Self-enhancing in perceptions of behaving unethica11y. Journal of Education for Business, 77 (1), pp. 21-27.

11. O'Leary, C. \& Cotter, D. (2000). The ethics of final year accountancy students: An international comparison. Managerial Auditing Journal, 15 (3), pp. 108-1 15.

12. Sankaran, S. \& Bui, T. (2003). Relationship between student's characteristics and ethics:Implications for educators. Journal of Instructional Psychology, 30 (3), pp. 240-253.

13. Saunders, Gary \& Wenzel, Loren, Individual Traits and Acceptance of Unethical Actions, Ethics \& Critical Thinking Journal, v. 2007, issue 4, p. 93-106. 


\section{APPENDIX I}

Average Responses to Statements in Each Scale and t-test for Difference in Means

$\mathrm{n}=382$ - US, n=34 - Indian

Ethics Principles

\begin{tabular}{|c|c|c|c|}
\hline $\begin{array}{l}\text { Please indicate your level of agreement with each of the following } \\
\text { statements. }\end{array}$ & US Students & Indian Students & Sig Diff* \\
\hline Honesty is always the best policy. & 1.95 & 1.82 & 0.380 \\
\hline Other people's welfare is more important than mine. & 3.31 & 2.85 & $\mathbf{0 . 0 3 8}$ \\
\hline I will never tolerate bribery in my life. & 2.70 & 2.18 & 0.028 \\
\hline
\end{tabular}

Strongly Agree = 1, Strongly Disagree = 6

Personal Values

\begin{tabular}{|l|r|c|c|}
\hline $\begin{array}{l}\text { Please indicate the level of importance each of the following factors has in } \\
\text { your ethical decision making. }\end{array}$ & US Students & Indian Students & Sig Diff* \\
\hline Self-principles. & 1.57 & 1.38 & 0.065 \\
\hline Law or regulations. & 2.05 & 1.79 & 0.128 \\
\hline
\end{tabular}

Very Important $=1$, Very Unimportant $=6$

Ethical Judgment

\begin{tabular}{|l|c|c|c|}
\hline $\begin{array}{l}\text { Please indicate your level of agreement with each of the following } \\
\text { statements. }\end{array}$ & US Students & Indian Students & Sig Diff* \\
\hline $\begin{array}{l}\text { Reporting a financial malpractice is required only if it involves a lot of } \\
\text { money. }\end{array}$ & 4.86 & 4.82 & 0.888 \\
\hline Bribery is acceptable if it is customary in the present environment. & 4.48 & 4.06 & 0.111 \\
\hline In some situations cheating is the right thing to do. & 4.76 & 3.71 & $\mathbf{0 . 0 0 1}$ \\
\hline
\end{tabular}

Strongly Agree = 1, Strongly Disagree = 6

*2 tailed significance of $t$-test for equality of means, equal variances not assumed.

Percentage Responses to Statements in Each Scale and t-test for Difference in Means $\mathrm{n}=382$ - US, n=34 - Indian

Perceived Positive Consequences

\begin{tabular}{|l|c|c|c|}
\hline $\begin{array}{l}\text { Please indicate how likely you think the following consequences of } \\
\text { unethical behavior are. }\end{array}$ & S Students & Indian Students & Sig Diff* \\
\hline I will get a lot of money. & 3.47 & 3.38 & 0.746 \\
\hline I will enjoy a better lifestyle. & 3.37 & 3.15 & 0.234 \\
\hline I will have better business opportunities. & 3.20 & 2.94 & 0.117 \\
\hline I will become more competitive. & 3.18 & 0.928 \\
\hline
\end{tabular}

Highly Unlikely = 1, Highly Likely = 6

Perceived Negative Consequences

\begin{tabular}{|l|r|c|c|}
\hline $\begin{array}{l}\text { Please indicate how likely you think the following consequences of } \\
\text { unethical behavior are. }\end{array}$ & US Students & Indian Students & Sig Diff* \\
\hline I will be legally punished. & 3.36 & 3.24 & 0.701 \\
\hline I will lose my job. & 3.33 & 3.50 & 0.612 \\
\hline I will humiliate myself. & 3.01 & 3.00 & 0.752 \\
\hline I will humiliate my family. & 3.42 & 3.15 & 0.411 \\
\hline
\end{tabular}

Highly Unlikely = 1, Highly Likely = 6

*2 tailed significance of $t$-test for equality of means, equal variances not assumed.

\section{APPENDIX II}

Average Responses to Each Scale and t-test for Difference in Means $\mathrm{n}=382$ - US, $\mathbf{n = 3 4}$ - Indian

\begin{tabular}{|l|c|c|c|}
\hline Scale & US Students & Indian Students & Sig Diff* \\
\hline Ethics Principles & 2.65 & 2.28 & $\mathbf{0 . 0 1 1}$ \\
\hline Personal Values & 1.81 & 1.59 & $\mathbf{0 . 0 3 0}$ \\
\hline Ethical Judgment & 4.70 & 4.20 & $\mathbf{0 . 0 1 0}$ \\
\hline Perceived Positive Consequences & 3.38 & 3.16 & 0.369 \\
\hline Perceived Negative Consequences & 3.28 & 3.20 & 0.775 \\
\hline
\end{tabular}

